\title{
Community Rating, Entry-Age Rating and Adverse Selection in Private Health Insurance in Australia
}

\section{Thomas Buchmueller}

Stephen Ross School of Business, University of Michigan and NBER, 701 Tappan St., Ann Arbor, MI 48109, U.S.A.

The regulation of health insurance is an important and often controversial issue. Rules intended to improve access to insurance for high-risk consumers have the potential to reduce overall coverage by inducing adverse selection. This paper examines the issue of adverse selection in the context of the market for private health insurance in Australia, before and after the implementation of a major policy reform in 2000. The policy, known as Lifetime Health Cover (LHC), created a financial incentive for consumers to enter the insurance market at earlier ages. I examine the extent of adverse selection prior to this reform and evaluate its effect on premiums. The results confirm that implementation of LHC induced a greater number of younger consumers into the market, resulting in lower average premiums.

The Geneva Papers (2008) 33, 588-609. doi:10.1057/gpp.2008.24

Keywords: private insurance; community rating; adverse selection

\section{Introduction}

The regulation of private health insurance is an important and often controversial issue. In many markets, regulations limit the extent to which insurers can set premiums based on the expected claims of subscribers, with the aim of making insurance affordable for high-risk consumers. The strongest form of premium regulation is pure community rating, which requires insurers to charge the same premiums to all subscribers, regardless of age, health status or any other characteristic that predicts medical expenditures. Under community rating, younger healthier consumers face higher premiums than they would in an unregulated market. If lower risk consumers respond to these actuarially unfair prices by dropping out of the market, premiums must increase to cover the cost of insuring the relatively higher risk consumers who remain. The increase in premiums can lead to further reductions in insurance purchases, a dynamic referred to as an "adverse selection death spiral."

Adverse selection has been a particular concern in Australia, where private insurance for hospital care and ancillary benefits supplements a universal public

\footnotetext{
* This research was done while I was a Packer Policy Fellow at the Centre for Health Economics Research and Evaluation at the University of Technology, Sydney. I thank the Australian Department of Health and Ageing for funding this project. I also thank Jim Butler, Paul Collins, Luke Connelly, Andrew Gale, Jane Hall, Charles Maskell-Knight, Elizabeth Savage, Rhema Vaithianathan and seminar participants at UTS, the University of Auckland and the University of Melbourne for helpful comments and suggestions.
} 


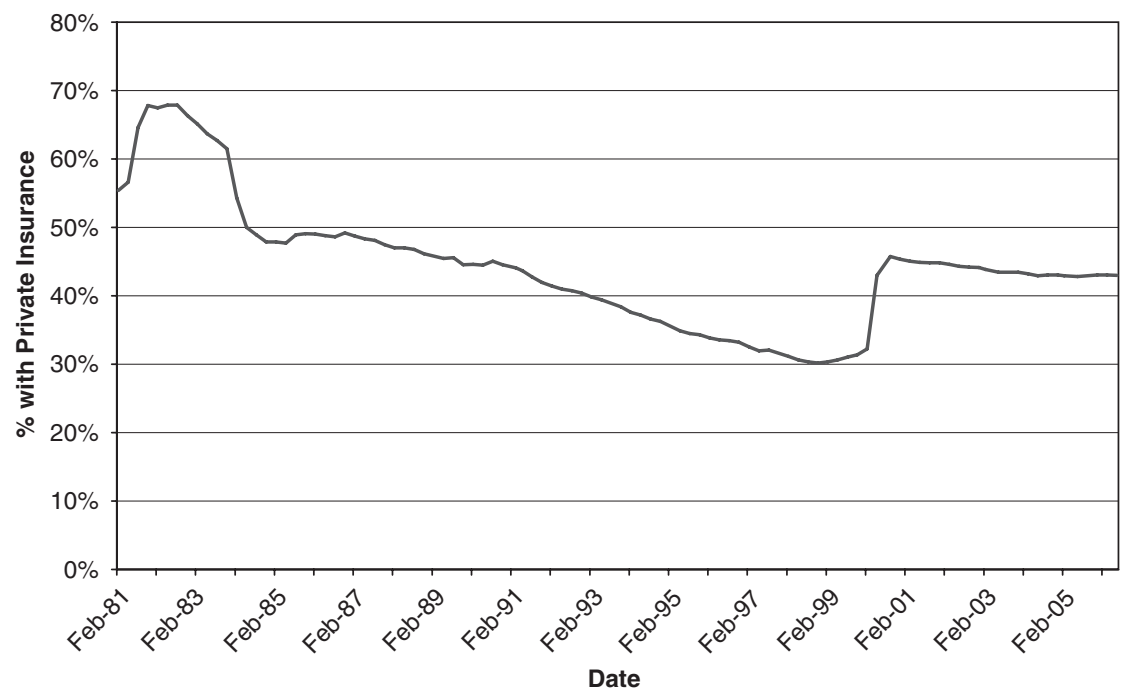

Figure 1. The per cent of Australians with private hospital insurance, 1981-2005

healthcare system. The number of Australians with private insurance began to fall in 1984, when universal public insurance (the Medicare programme) was established, and continued to fall steadily throughout the decade of the 1990s. Whereas in June 1984 50 per cent of Australians held private health insurance, by June 1997 only 32 per cent did (see Figure 1). Many observers have interpreted this trend as an adverse selection death spiral caused by the requirement that private health insurance premiums be community rated. ${ }^{1}$ Barrett and Conlon ${ }^{2}$ show that between 1989 and 1995 coverage fell more for younger consumers than for older ones, a pattern that is consistent with this interpretation.

Beginning in the late 1990s, the Australian government enacted several policies aimed at reversing the decline in private health insurance coverage. ${ }^{3}$ In 1997 a meanstested premium subsidy was introduced, along with a supplemental income tax of 1 per cent on higher income households that do not purchase private hospital insurance. Two years later, the means-tested subsidy was replaced with a 30 per cent rebate on all purchases of private insurance. Finally, in 2000, the government introduced the policy of Lifetime Health Cover (LHC), which modifies the community rating rules. LHC establishes a system of entry-age rating whereby premiums are based on an individual's age at the time she initially enrols in a private insurance fund. Specifically, there is a surcharge of 2 per cent for every year that the initial purchase is delayed after age 30 . So, for example, someone who first purchases private insurance

\footnotetext{
${ }^{1}$ Australian Industry Commission (1997); Barrett and Conlon (2003); Harper (2003); Gans and King (2003); Brown and Connelly (2005).

2 Barrett and Conlon (2003).

${ }^{3}$ For more details on these policies, see Hall et al. (1999); Butler (2002); and Hall and Savage (2005).
} 
at age 40 will pay 20 per cent more at that age than if she had been continuously insured since age 30 . LHC applies up to age 65 , which means a maximum possible penalty of 70 per cent. Individuals who first purchase private coverage after age 65 face no penalty.

Between the time that the LHC policy was announced in 1999 and when it came into effect in July 2000, individuals of any age could take up private coverage without being subject to the age-related surcharge. This amnesty period combined with an aggressive public marketing campaign had a dramatic effect on coverage. As shown in Figure 1, the percentage of Australians with private insurance jumped from 31 per cent in late 1999 to 45 per cent in late 2000. Since the various incentive policies were enacted over a short period of time, it is hard to disentangle their independent effects. Nonetheless, the general consensus of studies that analyse trends over this period is that the increase in coverage can be attributed mainly to LHC, rather than to the 1 per cent income tax surcharge or the 30 per cent premium subsidy. ${ }^{4}$

Because LHC is arguably the most important policy affecting health insurance in Australia since the establishment of Medicare in 1984, understanding its effects is critical for evaluating future policies affecting health insurance in that country. While several studies have analysed the effect of Australia's recent policy initiatives on the overall level of coverage, less attention has been paid to their effect on the demographics of the risk pool or on premiums.

In addition, an analysis of Australia's private insurance market offers more general insights regarding the economics of health insurance regulations. The Australian market, with its community rating rules and the recent changes to those rules, is an excellent case for studying the relationship between premium regulations and risk selection. Recent studies on U.S. insurance markets have analysed state laws restricting the use of age and other factors in the setting of premiums in this context. ${ }^{5}$ Because entry-age rating leads to a stronger relationship between subscriber risk and premiums than a system of pure community rating, LHC represents a "reverse experiment" relative to this previous literature. The Australian experience with LHC is also relevant to other countries where private health insurance supplements a universal public system. For example, a policy very similar to LHC has been proposed in Ireland. ${ }^{6}$ There are also important similarities between LHC and the rules determining premiums for the prescription drugs benefit that were added to the U.S. Medicare programme in 2006. In Medicare Part D, individuals who enrol when they are first eligible pay a community-rated premium, while those who delay enrolment pay a penalty that is based on how long they delay.

In this paper, I examine the issue of adverse selection in Australia from 1997 to 2005 , a period that provides several years of data both before and after the community rating rules were modified by the introduction of LHC. I address two related research

${ }^{4}$ Butler (2002); Frech et al. (2003); Ellis and Savage (2005); Palangkaraya and Yong (2005).

${ }^{5}$ For example, see Buchmueller and Jensen (1997); Zuckerman and Rajan (1999); Marquis and Long (2001/2002); Buchmueller and Dinardo (2002); Simon (2004) Monheit and Schone (2004); and Buchmueller and Liu (2005/2006).

${ }^{6}$ In Ireland, the policy of entry-age rating is referred to as "Lifetime Community Rating." The policy was introduced as part of legislation enacted in 2001, but as of early 2008 the policy has not yet been enacted. 
questions. First, what was the extent of adverse selection related to consumer demographics in the market just prior to the enactment of the policy? I answer this question by estimating the effect of adverse selection on average benefits paid by insurers, which is the primary determinant of private insurance premiums. I infer the effect of adverse selection by comparing actual benefits to an estimate of what average benefits would be if the risk pool were representative of the full Australian population. This approach represents an innovation relative to the existing literature on adverse selection in private health insurance markets, as prior studies in the area typically test for the presence of adverse selection and provide little information on the magnitude of the problem. The second question is how did the introduction of LHC alter the demographic composition of the private insurance risk pool and, in turn, average premiums? Here, I control for both changes in population demographics as well as for trends in hospital utilization and medical prices.

The results indicate that prior to the introduction of $\mathrm{LHC}$, the private health insurance pool was older than the general Australian population. As a consequence of this age difference, average premiums were approximately 10 per cent higher than they would have been if the private insurance risk pool had been representative of the full population. While this result is consistent with the argument that adverse selection was an issue in Australia's private health insurance market, the relatively small magnitude of the effect suggests that adverse selection was not a major factor driving the decline in private insurance coverage from the mid-1980s to the late 1990s. The second part of the analysis indicates that the introduction of LHC significantly altered the composition of the risk pool so that younger consumers were more strongly represented. This shift was large enough to mostly offset the prior adverse selection effect.

The next section summarizes the features of the Australian health insurance market that are most relevant to this study. The following two sections lay out the methods and data used in the analysis, respectively. The empirical results are presented in the penultimate section. The final section concludes.

\section{Private health insurance in Australia}

Private health insurance in Australia covers hospital care, including treatment at freestanding same-day facilities, and ancillary services, such as dental care, podiatry, chiropractic treatment and the cost of ambulance services. ${ }^{7}$ Private insurance cannot cover outpatient physician services or other types of primary care, which are financed by the public Medicare programme and some out-of-pocket payments by patients.

Individuals can purchase insurance for either hospital care or ancillary care, or both. Over 70 per cent of consumers with private insurance have coverage for both; coverage for hospital care alone is slightly more common than ancillary-only coverage (roughly 15 vs. 13 per cent of all individuals with private insurance in 2006.) Hospital benefits account for roughly three-quarters of all benefits paid by health funds. Since there is

\footnotetext{
${ }^{7}$ For a more detailed description of private health insurance in Australia and how it relates to the broader health care system, see Australian Industry Commission (1997) and Colombo and Tapay (2003).
} 
little or no age gradient with respect to ancillary benefits, the difference between current ancillary coverage premiums and what premiums would be if some form of risk rating were allowed is likely to be small. ${ }^{8}$ Because of this and the fact that LHC applies only to insurance policies that include hospital coverage, my analysis focuses on private hospital insurance.

Hospital insurance can be used for care received in public or private hospitals. The primary benefits of being a private patient in a public hospital are a greater ability to choose one's physician and a higher level of accommodations (i.e. a private room). However, private patients in public hospitals face higher out-of-pocket costs than if they were treated in the same facility as a public patient. Consequently, many individuals who have private insurance will still opt to be treated as a public patient when admitted to a public hospital.

Access to private hospitals represents a more important benefit of holding private insurance. Roughly 80 per cent of all hospital days reimbursed by private insurance are in private facilities. Private hospitals in Australia are less comprehensive than public hospitals and tend to focus mainly on elective procedures, especially ones for which public capacity is constrained. For example, private hospitals perform 70 per cent of knee replacements and a comparable percentage of cataract surgeries. In 2004-2005, the median time on a public hospital waiting list for these two procedures were 152 and 92 days, respectively. ${ }^{9}$ Private hospital insurance, therefore, improves access to certain types of care by allowing patients to "jump the queue." Private hospital insurance reimburses the cost of accommodation, medical services and prostheses. Prior to 1995 , coverage of physician charges was limited to the Medicare fee schedule, which is often lower than the fees actually charged by physicians. Patients were responsible for any difference between actual fees and the schedule. In response to concern about privately insured patients facing high and often unexpected out-of-pocket costs, legislation was enacted in 1995 and 2000 to allow insurers to cover part or all of this "gap."

Regulations pertaining to private insurance are set out in the National Health Act of 1953 and the Health Insurance Act of 1973. The National Health Act states that a registered health fund must "ensure that its constitution and rules, and its actions, are at all times consistent with the principles of community rating." Specifically, health funds are prohibited from discriminating among consumers on the basis of health status, age, gender, sexual orientation or religious belief.

Premiums are, however, allowed to vary across different products offered by a single insurer to reflect the claims experience for each product. This is significant because the regulations allow insurers considerable flexibility in the design of their products, including the ability to offer policies that explicitly exclude coverage for certain conditions or treatments. ${ }^{10}$ By reducing the degree of pooling, these exclusions mitigate the impact of community rating on younger, healthier consumers. For

\footnotetext{
${ }^{8}$ Mean ancillary benefits are roughly the same for children between the ages of 10 and 14 as for adults between the ages of 30 and 34 (roughly \$20 per month in 2006). After age 34, mean benefits increase by between 1 and 2 per cent per year up to age 70 and decline with age thereafter.

9 Australian Institute of Health and Welfare (2006).

${ }^{10}$ Prior to 1995 , insurers could restrict the coverage of specic treatments in private hospitals, but not in public hospitals. Since then, insurers can offer policies that exclude certain treatments in any setting.
} 
example, young adults can reduce their premiums (and the implicit subsidies they pay to older consumers) by purchasing policies that exclude coverage for such things as coronary care, joint replacement, renal dialysis or cataract surgery; other consumers may choose not to take coverage for pregnancy. Roughly one-third of all hospital insurance policies have some exclusion or limitation. Consumers can further reduce their premiums by choosing policies with deductibles or other forms of cost sharing. The percentage of policies with deductibles has increased steadily over time; in 2005 , roughly 60 per cent of the hospital policies sold in Australia had a deductible. The combination of exclusions, deductibles and other forms of cost-sharing results in a high degree of product differentiation in the Australian market.

The timing of the policy initiatives aimed at increasing private insurance coverage makes it difficult to precisely identify the effects of different components of the reforms. That being said, the results of several studies suggest that LHC had the strongest effect. Butler ${ }^{11}$ and Frech et al. ${ }^{12}$ use time series data to estimate the effects of the various policies. The data show little break in the decline in coverage in 1997 when the tax surcharge on high earners without private insurance and the means-tested premium subsidy were enacted. Coverage stabilized after 1999 when the means-tested subsidy was replaced with the 30 per cent premium subsidy for all subscribers. Relative to the prior downward trend, Frech et al. ${ }^{13}$ estimate that this policy increased coverage by 11 per cent. As shown in Figure 1, coverage increased dramatically in 2000, during the period where consumers could take up coverage without facing the LHC surcharges. Therefore, they attribute the bulk of the overall increase to LHC.

Palangkaraya and Yong ${ }^{14}$ attribute greater importance to the 30 per cent subsidy. analysing micro-data from 1995 and 2001, they conclude that the effect of the rebate was almost as large as the effect of LHC. This result is driven by the assumption that any effects of LHC should have been limited to adults between the ages of 30 and 65, for whom the LHC surcharges are relevant. This means that they attribute coverage increases among younger and older consumers to the 30 per cent rebate. In contrast, Ellis and Savage, ${ }^{15}$ who also use micro-data, estimate models that allow for the possibility that the implementation of LHC may have affected coverage in ways other than via the entry-age premium surcharges. They find a positive effect of LHC even among age groups not immediately subject to the age rating, a result that they attribute to the massive marketing campaign conducted by the government to promote the policy. Their results suggest that the 30 per cent rebate had little effect on coverage.

In light of the results from these studies and the fact that the LHC was the only policy that was designed specifically to affect the demographic structure of the risk pool, I attribute changes in demographics and average benefits after 2000 to LHC. However, allowing for the possibility that some of the credit belongs to the 30 per cent

\footnotetext{
11 Butler (2002).

${ }^{12}$ Frech et al. (2003).

13 Ibid.

${ }^{14}$ Palangkaraya and Yong $(2005,2007)$.

${ }^{15}$ Ellis and Savage (2005).
} 
premium subsidy or the 1 per cent income tax surcharge does not alter the analysis, only the way in which the results are described.

\section{Analytical framework}

Adverse selection occurs when higher risk consumers exhibit a greater demand for insurance relative to other consumers who face the same prices. Empirical tests for adverse selection commonly involve comparing the risk characteristics of individuals that do and do not purchase insurance. For example, in their study of private health insurance in Australia, Barrett and Conlon ${ }^{16}$ estimate probit models of private coverage as a function of age, self-reported health and the presence of several specific health conditions. Other studies use a similar approach to test for adverse selection in the market for "Medigap" insurance in the U.S. ${ }^{17}$ and private health insurance in Israel $^{18}$ and France. ${ }^{19}$

There are two main limitations of this approach, which I attempt to address by using an alternative methodology. The first is that with regression models that include several different risk proxies, it is not uncommon for different proxies to have opposing effects. For example, Barrett and Conlon $^{20}$ find that age is positively related to insurance coverage and that the age gradient grew steeper over time. They interpret this pattern as evidence of an adverse selection spiral. However, they also find that individuals in fair or poor health are less likely to purchase insurance than those in good or excellent health (a result that suggests "advantageous selection") while other health proxies are found to have no significant effect. Thus, the overall effect of selection is not easily signed. Second, even when the coefficients on different risk proxies have the same sign, it is difficult from a comparison of risk characteristics to gauge the magnitude of the effect, or its practical implications.

In this paper, I compare actual medical spending covered by insurance to a counterfactual value to calculate a dollar-denominated measure of the extent of adverse selection. This calculation relies on the fact that under community rating, health insurance premiums will be a function of the demographic and risk characteristics of the risk pool. If the pool of insured individuals ages, premiums will rise. Similarly, an influx of young consumers into the market, all else being equal, will cause premiums to fall.

My focus here is on the effects of basic demographic characteristics - age and gender. This is driven in part by issues of data availability, but also because of policy considerations. Unlike the case of the U.S., where policies restricting the use of health status in underwriting have been the subject of considerable debate, in Australia the concept of community rating is widely embraced. Thus, while it would be interesting from an academic perspective to understand more about selection based on risk

\footnotetext{
${ }^{16}$ Barrett and Conlon (2003).

${ }^{17}$ Ettner (1997); Hurd and McGarry (1997); Fang et al. (2006).

${ }^{18}$ Shmueli (2001).

${ }^{19}$ Buchmueller et al. (2004).

${ }^{20}$ Barrett and Conlon (2003).
} 
factors other than age, policies that would allow insurers to use those factors in underwriting are unlikely. ${ }^{21}$

Under community rating, the relationship between enrollee demographics and premiums can be summarized as follows:

$$
\begin{gathered}
\Pi_{t}=(1+a) \bar{B}_{t} \\
\bar{B}_{t}=\sum_{d} S_{d t} \times M_{d t} .
\end{gathered}
$$

Eq. (1) shows that average premiums $(\Pi)$ depend on average benefits paid $(\bar{B})$ plus insurers' administrative costs, or "loading." Average benefits, in turn, depend on the share of enrollees in each mutually exclusive demographic group $\left(S_{d}\right)$ and mean reimbursed health spending for each group $\left(M_{d}\right)$.

This framework is useful for calculating an intuitive monetary measure of the extent of adverse selection in the market and for analysing the impact of demographic changes on premiums. The impact of adverse selection related to demographic characteristics can be estimated by comparing actual benefits paid by insurers to a counterfactual measure calculated by assuming that the risk pool had a different demographic composition.

One logical counterfactual for estimating the cost of adverse selection associated with community rating would be the risk distribution that would result if premiums were allowed to be risk-rated. The main appeal of this counterfactual is that it corresponds to one possible, albeit extreme (and in the Australian context, unlikely) policy: the elimination of all regulations concerning premiums. However, estimation of this distribution would require a complex simulation incorporating a number of significant but untestable assumptions. First, it would be necessary to make assumptions about how insurers set premiums in a completely unregulated market. While claims data could be used to approximate actuarially fair premiums, evidence from the U.S. suggests that even in the absence of rating regulations, private health insurance premiums tend not to be fully risk rated. ${ }^{22}$ Given a distribution of premiums, estimating the distribution of coverage requires assumptions about the price and income elasticities of demand for different demographic groups. There are no reliable estimates of these parameters for Australia.

An alternative benchmark can be constructed by assuming that the demographic composition of the risk pool mirrors the distribution for the entire population. This is the implicit counterfactual in the aforementioned studies that test for adverse selection in individual survey data by regressing insurance coverage on age or other individual characteristics that predict medical expenditures. This counterfactual measure of average benefits is

$$
\bar{B}_{t}^{*}=\sum_{d} S_{d t}^{*} \times M_{d t}
$$

\footnotetext{
${ }^{21}$ Brown and Connelly (2006) propose an interesting alternative to LHC that involves subsidies based on a fuller definition of risk.

${ }^{22}$ Pauly and Herring (1999); Herring and Pauly (2001).
} 
where $S_{d}^{*}$ represents the share of the total population in demographic group $d$. The cost of adverse selection relating to demographics can then be stated as

$$
C_{t}=\bar{B}_{t}-\bar{B}_{t}^{*}=\sum_{d}\left(S_{d t}-S_{d t}^{*}\right) \times M_{d t}
$$

Because insured medical expenditures are not observed for people without insurance, it is necessary to use $M_{d t}$ to compute the counterfactual measure of benefits. That is, data limitations require ignoring selection within demographic groups. It is not clear how this assumption affects estimates of the cost of adverse selection. On the one hand, conventional theoretical models of risk selection would predict that under community rating individuals with private insurance will be in poorer average health than those who opt to go without private coverage. If this is the case, $C_{t}$ will understate the overall degree of adverse selection at a point in time. On the other hand, there is considerable evidence from Australia that individuals in poor health are less likely to have private insurance. ${ }^{23}$ These findings suggest that $C_{t}$ will overstate the extent to which premiums are higher than they would be if the risk pool were representative of the general population in all respects.

Whichever case may hold, measures calculated assuming no risk selection within age groups are still useful for analysing the extent of adverse selection under the pure community rating policy regime. As noted in the introduction, the conventional wisdom about a death spiral in Australia's private health insurance market was based on the observation that there was a positive age gradient in coverage rates and that the gradient was getting steeper over time. Eq. (4) provides a dollar-denominated measure of the extent of age-related adverse selection.

As described above, the goal of LHC was to increase the number of Australians with private insurance by inducing a greater number of younger consumers to purchase coverage. We can estimate the effect of LHC on premiums by comparing average benefits before and after the policy went into effect. However, a simple pre-post comparison will be confounded by other changes affecting benefits, such as increasing medical prices, changes in benefit design and changes in utilization patterns. There were several changes around the time of Australia's private insurance reforms that have implications for paid benefits and premiums. ${ }^{24}$ These confounding factors affect premiums through an effect on $M_{d}$, the demographic group-specific mean level of spending. Therefore, to obtain an unbiased estimate of the effect of LHC, it is necessary to hold constant changes in $M_{d}$. This can be done by decomposing the

\footnotetext{
${ }^{23}$ Barrett and Conlon (2003); Hindle and McAuley (2004); Ellis and Savage (2005); Doiron et al. (2008).

${ }^{24}$ As noted above, since the mid-1990s there has been an increase in private insurance coverage for the "gap" between the total fee charged by medical specialists and the Medicare scheduled fee. At the same time, there has been a gradual increase in the prevalence of deductibles and other forms of cost sharing. These two trends will both affect premiums, though in opposite directions. Also, in the late 1990s and early 2000s dramatic increases in the price of prostheses contributed to increasing medical inflation, which put upward pressure on premiums for hospital insurance (Gale and Brown (2003); Private Health Insurance Administration Council (2006)).
} 
change in average benefits between two periods as follows:

$$
\begin{aligned}
\Delta \bar{B}= & \bar{B}_{1}-\bar{B}_{0}=\sum_{d}\left(S_{d 1}-S_{d 0}\right) \times M_{d 0} \\
& +\sum_{d} S_{d 1} \times\left(M_{d 1}-M_{d 0}\right) .
\end{aligned}
$$

The first term on the right hand side is the portion of the change in average benefits that can be explained by demographic changes, holding constant medical care prices, health insurance benefit design and patterns of utilization. The second term represents the effect of changes in these other factors. ${ }^{25}$

The first term can be interpreted as representing the effect of LHC relative to the baseline situation, that is, assuming that in the absence of the policy the demographic composition of the risk pool would have remained constant. But, this assumption is questionable, especially given prior demographic trends. An alternative approach is to assume that if LHC had not gone into effect the risk pool would have aged in a similar manner as the entire population. It is straightforward to calculate $\Delta \bar{B}^{*}$, an analog to Eq. (5) based on the counterfactual measure of average benefits. Then, we can calculate the following "difference in differences":

$$
\begin{aligned}
\Delta \bar{B}-\Delta \bar{B}^{*}= & \sum_{d}\left[\left(S_{d 1}-S_{d 0}\right)-\left(S_{d 1}^{*}-S_{d 0}^{*}\right)\right] \times M_{d 0} \\
& +\sum_{d}\left(S_{d 1}-S_{d 1}^{*}\right) \times\left(M_{d 1}-M_{d 0}\right) .
\end{aligned}
$$

Here, the first term represents the effect of the change in risk pool demographics relative to the change for the population. Given that prior to the introduction of LHC the risk pool was ageing slightly more rapidly than the population, this will produce a conservative estimate of the policy effect.

\section{Data}

The main source of data for this analysis is the Private Health Insurance Administration Council (PHIAC), an independent public agency that regulates Australia's private health insurance industry in accordance with policies determined by the Commonwealth government. PHIAC compiles quarterly data by age and sex categories. ${ }^{26}$ The age categories are groupings of 5 years, ( 0 to 4,5 to 9,10 to 14 and so on) up to age 94 plus an additional category for enrollees aged 95 and older. This results in a total of 40 mutually exclusive demographic groups (20 age categories for males and 20 for females). Among the variables reported by PHIAC are the number of persons with hospital insurance and the average reimbursed benefits for each demographic group, which can be used to construct $S_{d t}$ and $M_{d t}$, respectively.

\footnotetext{
${ }^{25}$ The decomposition can also be calculated using $M_{d 1}$ to weight the demographic changes (in the first term on the right hand side) and $S_{d 0}$ to weight the change in $\mathrm{M}$ (the second term). The results for the two approaches are essentially identical.

26 These data are available online at www.phiac.gov.au.
} 
Data aggregated by age and sex are available beginning in the third quarter of 1997; I use data through the fourth quarter of 2005. Between 1997 and 2005, general inflation in Australia averaged 2.8 per cent per year. I use the average consumer price index for Australia's eight capital cities to convert all monetary figures to 2005 Australian dollars.

Calculating counterfactual measures of average benefits under the assumption that the privately insured risk pool is representative of the population requires data on the age and sex distribution for all of Australia. These data come from the Australian Bureau of Statistics (ABS), which provides annual tabulations of the number of males and females at each age. ${ }^{27} \mathrm{I}$ aggregate these data into the same 5-year categories for which the PHIAC data are reported. ${ }^{28}$

The PHIAC data have several advantages relative to the survey data used in most prior studies of adverse selection. The most important is that household survey data sets typically have little or no information on medical claims. At best, surveys have self-reports of recent utilization - for example, the number of doctor visits or hospital episodes over a certain period of time. In contrast, the PHIAC benefits data represent 100 per cent of reimbursed claims. Because they are collected as part of a reinsurance system that determines transfers among health funds depending on their claims experience, the quality of the data is high. Quarterly submissions are scrutinized by PHIAC analysts and data from individual funds are audited by external auditors on an annual basis. In addition to their high quality, the frequency of the PHIAC data is an advantage relative to survey data. As will be shown, estimates of the effect of LHC are somewhat sensitive to whether the post-reform data are taken from just after the policy went into effect or several years later.

\section{Results}

Trends in enrolment and demographics, 1997-2005

Before considering the effect of adverse selection on average benefits and the impact of LHC, it is useful to first examine how the demographics of the risk pool compared to the population before and after the policy change. Table 1 presents basic information

\footnotetext{
${ }^{27}$ The Australian census is conducted every 5 years. For my analysis, the relevant census years are 1996 and 2001. In between these years the ABS estimates the age and sex distribution of the population using annual data on births (by sex) and deaths (by age and sex) and derived profiles of migration. The data and a report describing the details of this procedure (Australian Bureau of Statistics (1995)) are available online at www.abs.gov.au.

${ }^{28}$ It is worth noting that not everyone in the population will be truly "in the market" for private insurance. Certain military veterans and their survivors are entitled to health benefits through the Department of Veterans Affairs (DVA). Roughly 240,000 Australians hold DVA Gold Cards, which provide a level of benefits comparable to private health insurance. Because they are disproportionately elderly, adjusting the population data to remove them would reduce the measure of counterfactual benefits slightly. The population data also include short-term visitors, such as students and people on work visas. Doing a similar adjustment for this group, which is disproportionately young, would have the opposite effect on the analysis. These types of adjustments would have essentially no effect on estimates of changes in the counterfactual level of benefits.
} 
Table 1 Trends in private insurance coverage and risk pool demographics, 1997-2005

\begin{tabular}{|c|c|c|c|c|c|}
\hline & 1997 & 1999 & 2001 & 2003 & 2005 \\
\hline Total enrolment & $5,917,572$ & $5,846,197$ & $8,731,021$ & $8,667,566$ & $8,741,899$ \\
\hline per cent of population & $34.9 \%$ & $33.4 \%$ & $44.6 \%$ & $43.1 \%$ & $42.1 \%$ \\
\hline \multicolumn{6}{|l|}{ Average age } \\
\hline a. Insured persons & 39.4 & 39.9 & 38.1 & 38.8 & 39.5 \\
\hline b. Australian population & 35.4 & 35.8 & 36.3 & 36.7 & 37.1 \\
\hline Difference $(a-b)$ & 4.1 & 4.0 & 1.8 & 2.1 & 2.4 \\
\hline \multicolumn{6}{|l|}{ per cent over age 65} \\
\hline a. Insured persons & $14.5 \%$ & $14.5 \%$ & $11.0 \%$ & $11.8 \%$ & $12.7 \%$ \\
\hline b. Australian population & $12.1 \%$ & $12.3 \%$ & $12.6 \%$ & $12.8 \%$ & $13.12 \%$ \\
\hline Difference $(a-b)$ & $2.4 \%$ & $2.2 \%$ & $-1.6 \%$ & $-1.0 \%$ & $-0.4 \%$ \\
\hline \multicolumn{6}{|l|}{ per cent male } \\
\hline a. Insured persons & $47.5 \%$ & $47.4 \%$ & $48.3 \%$ & $48.3 \%$ & $48.3 \%$ \\
\hline b. Australian population & $49.7 \%$ & $49.6 \%$ & $49.7 \%$ & $49.7 \%$ & $49.7 \%$ \\
\hline Difference $(a-b)$ & $-2.2 \%$ & $-2.2 \%$ & $-1.3 \%$ & $-1.4 \%$ & $-1.4 \%$ \\
\hline
\end{tabular}

on private hospital insurance enrolment and the demographics of the risk pool for selected years from 1997 to 2005. Two measures of age are displayed: mean age and the per cent over age 65 .

In 1997 there was a 4-year difference in mean age between the risk pool and the population (39.4 vs. 35.4) and a 2.4-point difference in the per cent over age 65 (14.5 vs. 12.1 per cent). These data can be compared to similar figures for 1990 and 1995 presented in a report by the Australian Industry Commission. ${ }^{29}$ In 1990, the private insurance risk pool was only slightly older than the general population. The mean age for the pool was 34.3, compared to a population mean of 34, and 11 per cent of the risk pool was over age 65 , compared to 10 per cent of the population. By 1995, the age gap had widened to 2.4 years (37.4 vs. 34.9) and there was a two-point gap in the per cent over 65 (13.9 vs. 11.9 per cent). Thus, it is clear that the risk pool was gradually ageing relative to the population over most of the 1990s.

The 30 per cent premium subsidy went into effect in January 1999. Total enrolment in 1999 was slightly lower than the level in 1997, but slightly higher than in 1998 (data not shown). This is consistent with the conclusion of prior studies that the subsidy halted the long decline in private insurance coverage. The data in Table 1 suggest that this policy had little or no impact on risk pool demographics. The difference between the risk pool and the population in terms of mean age and per cent over age 65 remained essentially constant between 1997 and 1999 .

In contrast, both the enrolment and demographic data indicate a strong effect of LHC. Between 1999 and 2001, the number of people with hospital insurance increased by almost 50 per cent, from under 6 million to almost 9 million. The consumers that

\footnotetext{
${ }^{29}$ Australian Industry Commission (1997).
} 


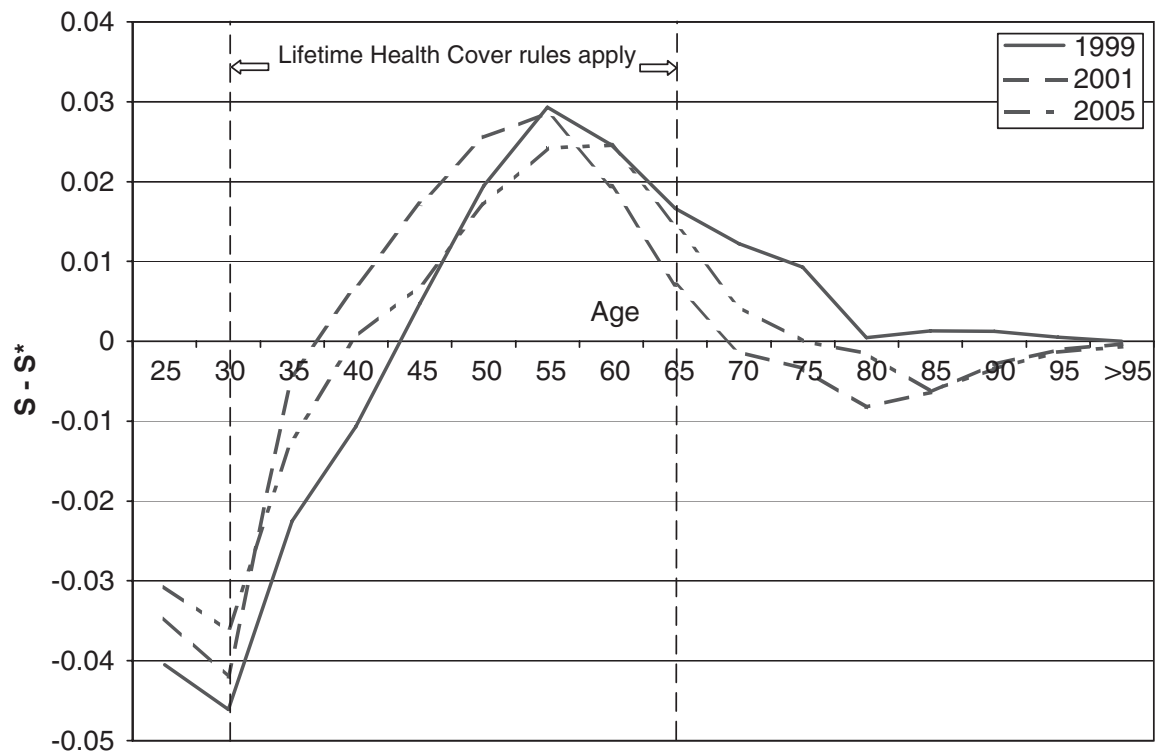

Figure 2. Differences in age distribution: Insured risk pool vs. the total population

took up coverage in response to LHC were younger on average than the existing pool, causing the average age of the risk pool to decrease by almost 2 years. Since the population was ageing over this period, the gap in mean age fell roughly by half. The per cent of the population over age 65 also fell considerably, from 14.5 to 11 per cent. In fact, by 2001 adults over age 65 were actually under-represented in the pool relative to the population. enrolment remained essentially constant from 2001 to 2005 . Both the population and the insured risk pool aged over that period, though the change was slightly larger for the risk pool.

Figure 2 provides a more complete picture of these demographic changes. The figure plots $S_{d}-S_{d}^{*}$, the difference between the share of the risk pool falling in each age group and the share of the total population in that age group. A positive value signifies that the age group is over-represented in the risk pool, whereas a negative value means that the group is under-represented. Since children are almost always enrolled as dependents, the graph is limited to adults aged 20 and older. For the sake of clarity, data are presented for only 3 years: 1999, 2001 and 2005.

The graph for 1999 shows that adults under age 40 were under-represented in the risk pool, those between the ages of 40 and 80 were over-represented and the share over age 80 was roughly the same as in the general population. The coverage effects of LHC were most dramatic for adults between the ages of 30 and 40. By 2001, the percentage of insured adults between the ages of 30 to 34 was only slightly lower than the population percentage and 35- to 39-year-olds were now over-represented, rather than under-represented in the risk pool. Adults in their 20s, who were not affected by the LHC rules, remained under-represented in the risk pool. By 2005, adults under age 40 were under-represented in the risk pool, though less so than in 1999. The percentage 
of adults between the ages of 40 and 75 was higher in the risk pool than the general population, while the share over 75 was slightly lower in the pool.

There are two important limitations of this type of demographic comparison. First, while it is clear that the ageing of the risk pool relative to the population over the $1990 \mathrm{~s}$ should have contributed to an increase in insurance premiums, demographic data alone provide no insight on the magnitude of this effect. Second, in the post-LHC period, the effect on premiums of demographic differences between the risk pool and the population cannot even be signed. The higher mean age for the risk pool suggests adverse selection, which would raise premiums. But the fact that a smaller share of the risk pool is over age 65 implies an effect in the opposite direction. A comparison of actual and counterfactual measures of average benefits addresses both of these limitations.

\section{The effect of adverse selection on average benefits}

Table 2 and Figure 3 present comparisons of actual average benefits, $\bar{B}$, and the counterfactual measure, $\bar{B}^{*}$ for each year from 1997 to 2005 . The data presented correspond to the value of each variable for the third quarter of each year. ${ }^{30}$

Since administrative costs represent between 12 and 16 per cent of premiums collected, the $\$ 650$ in per capita benefits paid in 1997 translates to an annual premium of between $\$ 725$ and $\$ 760$. By construction, the difference between $\bar{B}$ and $\bar{B}^{*}$ in any year can be explained entirely by differences in demographics. Thus, comparing actual benefits to the counterfactual measure of \$590 indicates that in 1997 average benefits and, assuming a constant loading factor, average premiums - were 10 per cent higher than they would have been in the absence of adverse selection. The data for 1998 and 1999 indicate a similar per cent effect.

One way to obtain a rough gauge of the importance of this effect is to calculate a "back of the envelope" estimate of what enrolment would have been in 1997-1999 had premiums been 10 per cent lower. This calculation requires an estimate of the premium elasticity of the decision to purchase insurance. Butler ${ }^{31}$ estimates the price elasticity of demand for hospital insurance in Australia to be between -0.36 and -0.50 . Multiplying these elasticity estimates by the 10 per cent increase in premiums implies that in the absence of age-related adverse selection enrolment would have been between only 3 and 5 per cent higher. This effect is small relative to the 36 per cent decline in coverage that occurred in the decade and a half after the introduction of universal public insurance. ${ }^{32}$

${ }^{30}$ The graph plots annual data rather than quarterly data because the population demographics are measured annually. I use data from a single quarter rather than the average for the full year because for 1997 only the last two quarters are available and there is significant seasonality in the data. On average third quarter benefits are 2.8 per cent higher than the other three quarters. I account for this in constructing annual figures.

31 Butler (1999).

${ }^{32}$ Because premiums are not observed in his data, Butler's elasticity estimates are based on an imputed measure of price that is a negative function of age. If age has an independent positive effect on the demand for insurance, his elasticity estimates may be overstated. Several U.S. studies that exploit 
The Geneva Papers on Risk and Insurance - Issues and Practice 602

Table 2 Trends in benefits per private health insurance enrollee, 1997-2005: Actual and counterfactual

\begin{tabular}{|c|c|c|c|c|}
\hline \multirow[b]{2}{*}{ Year } & \multicolumn{4}{|c|}{ Annual benefits per person (\$) } \\
\hline & $\begin{array}{c}\text { Actual } \\
\quad(\bar{B})\end{array}$ & $\begin{array}{c}\text { Counterfactual } \\
\qquad\left(\bar{B}^{*}\right)\end{array}$ & $\begin{array}{c}\text { Difference } \\
\left(C=\bar{B}-\bar{B}^{*}\right)\end{array}$ & $\%$ Difference \\
\hline 1997 & 650.12 & 590.25 & 59.87 & 10.1 \\
\hline 1998 & 671.78 & 607.17 & 64.61 & 10.6 \\
\hline 1999 & 616.50 & 561.48 & 55.02 & 9.8 \\
\hline 2000 & 440.91 & 469.65 & -28.74 & -6.1 \\
\hline 2001 & 544.54 & 562.16 & -17.63 & -3.1 \\
\hline 2002 & 582.63 & 596.59 & -13.96 & -2.3 \\
\hline 2003 & 626.87 & 633.29 & -6.41 & -1.0 \\
\hline 2004 & 669.65 & 666.61 & 3.03 & 0.5 \\
\hline 2005 & 689.14 & 677.88 & 11.26 & 1.7 \\
\hline
\end{tabular}

Notes: Figures are annualized measures based on data for the third quarter of each year and are expressed in $\$ 2005$.

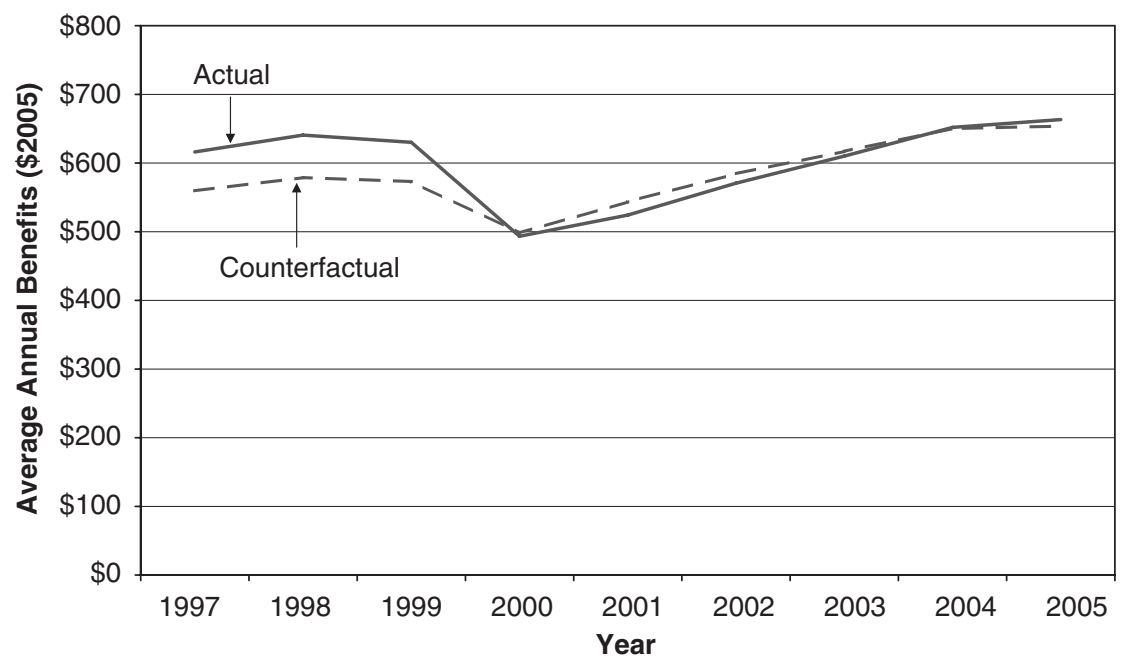

Figure 3. Trends in actual and counterfactual benefits per capita

After the introduction of LHC, average annual benefits fell to $\$ 441$ in 2000 from $\$ 616$ in 1999 . This dramatic change was only partly due to the improvement in the risk pool, as can be seen by the fact that $\bar{B}^{*}$ also declined even though the population was ageing. The explanation is that group-specific spending per capita $(M)$ was falling over

plausibly exogenous variation in price obtain take-up elasticity estimates in the range of -0.10 or below (Chernew et al. (1997); Blumberg et al. (2001); Buchmueller and Ohri (2006)). However, because Australia's Medicare system provides a better substitute for private insurance than is available to most U.S. consumers, it seems likely that the demand for insurance is more elastic in Australia. 
this period as well. We will return to the relative importance of changes in demographics and changes in group-specific mean spending below. Focusing for now on the role of demographics, we see that between 2000 and 2003 the actual level of benefits per capita was actually lower than the counterfactual. Thus, it appears that the surge in enrolment caused by the introduction of LHC altered the composition of the risk pool to more than offset the effect of the previous adverse selection.

Mean per capita benefits bottomed out in 2000 and then increased steadily, reaching a level of $\$ 689$ by 2005 . As shown in Table 1, even though total enrolment remained relatively constant over this period, the risk pool aged slightly more rapidly than the overall population. The cost implication of this is that actual benefits increased faster than the counterfactual and by 2005 were 1.7 per cent higher than what they would have been if the risk pool were representative of the population. However, in considering this trend it is important to keep in mind that after July 2000, new subscribers between the ages of 30 and 65 were subject to the LHC surcharge. These higher premium payments serve to (at least partially) offset the cost associated with the ageing of the risk pool. As of the end of 2005, 5 per cent of adult enrollees were subject to a surcharge, paying an average penalty of 22 per cent. Overall, this increased premium revenues by 1.2 per cent. ${ }^{33}$

\section{Decomposition results}

The decomposition analysis described in Eqs. (5) and (6) can be used to disentangle the changes in average benefits caused by changing demographics - which can be attributed to the introduction of LHC - from other factors affecting hospital claims. Table 3 presents decomposition results for two 5-year periods (1997-2001 and 20012005) and the full 9-year period (1997-2005).

The two 5-year periods are quite different in terms of how average benefits were changing and the determinants of those changes. During the first period, changes in both demographics and hospital utilization contributed to a reduction in average benefits. The decomposition shows that the improvement in the risk pool accounted for roughly three-fifths of the total decline over this period. Had utilization patterns and medical prices remained constant, average benefits would have fallen by $\$ 61.93$, or just under 10 per cent of the 1997 level. ${ }^{34}$ This figure can be interpreted as an estimate of the immediate effect of LHC under the assumption that the demographic composition of the risk pool would have remained constant between 1997 and 2001. But, as discussed above, it will under-estimate the effect if in the absence of the policy

${ }^{33}$ Data on the number of individuals in each 5-year age group subject to LHC surcharges is presented quarterly in the PHIAC A Report, which is available online.

${ }^{34}$ As noted, an alternative decomposition formula is one where the demographic changes are weighted by the group-specific benefits in the second period and the changes in benefits are weighted by the demographics for the second period. Using this approach, the effect of changing demographics on average benefits is $-\$ 61.41$ instead of $-\$ 61.93$. The decomposition results are more sensitive to whether constant or nominal dollars are used. In nominal terms, average benefits fell by $\$ 38$ between 1997 and 2001 , from $\$ 515$ to $\$ 477$. Ninety-four per cent of this nominal change can be attributed to the change in demographics. 
Table 3 Decomposition results for actual and counterfactual benefits

\begin{tabular}{|c|c|c|c|}
\hline & $\begin{array}{l}\text { Actual } \\
(\bar{B})\end{array}$ & $\begin{array}{c}\text { Counterfactual } \\
\qquad\left(\bar{B}^{*}\right)\end{array}$ & $\begin{array}{c}\text { Difference } \\
\left(\bar{B}-\bar{B}^{*}\right)\end{array}$ \\
\hline \multicolumn{4}{|l|}{ A. $1997-2001$} \\
\hline Total change & -105.58 & -28.09 & -77.87 \\
\hline \multicolumn{4}{|l|}{ Change due to: } \\
\hline Demographics & -61.93 & 19.87 & -82.20 \\
\hline Utilization, prices & -43.66 & -47.96 & 4.33 \\
\hline B. 2001-2005 & 144.60 & 115.72 & 29.02 \\
\hline \multicolumn{4}{|l|}{ Total change } \\
\hline \multicolumn{4}{|l|}{ Change due to: } \\
\hline Demographics & 43.14 & 19.56 & 22.90 \\
\hline Utilization, prices & 101.46 & 96.15 & 5.34 \\
\hline C. 1997-2005 & 39.02 & 87.63 & -48.85 \\
\hline \multicolumn{4}{|l|}{ Total Change } \\
\hline \multicolumn{4}{|l|}{ Change due to: } \\
\hline Demographics & -18.59 & 40.41 & -59.00 \\
\hline Utilization, prices & 57.61 & 47.22 & 10.45 \\
\hline
\end{tabular}

Notes: See eqs. (5) and (6) for the decomposition formulae.

change the risk pool would have aged. The decomposition results for the counterfactual measure show that if the risk pool had aged at the same rate as the overall population (and utilization and prices were held constant) average benefits would have increased by $\$ 19.87$. The difference-in-differences estimate is therefore that the introduction of LHC reduced average benefits by $\$ 82.20$ (13 per cent of the base level) between 1997 and 2001.

The decline in group-specific spending between 1997 and 2001 can be seen as a temporary by-product of the insurance reforms. Private hospital insurance policies in Australia typically require a 1-year probationary period before subscribers can collect benefits related to pre-existing conditions. Individuals who took up private insurance during the LHC grace period were subject to probationary periods between mid-2000 and mid-2001. A more detailed analysis suggests that this explains the decline in $M_{d}$ over this period. Group-specific spending can be further broken down as $M_{d t}=E_{d t} \times P_{d t}$ where $E_{d t}$ is the number of hospital episodes per capita (essentially the quantity of care) and $P_{d t}$ represents spending per episode (the price). An analysis of these components reveals that average episodes decreased by 13 per cent between 1997 and 2001, while there was little change (in constant dollars) in the mean cost per episode. ${ }^{35}$

${ }^{35}$ The per cent changes can be estimated by treating each age/sex/quarter cell as a separate observation and running regressions of the form:

$$
\ln Y_{d t}=\alpha^{\prime} Q U A R T E R+\beta^{\prime} Y E A R+\delta_{d}+u_{d t}, \quad Y=(E, P)
$$

where $Q U A R T E R$ and YEAR are vectors of quarter and year dummies, respectively, and $\delta_{d}$ represents a fixed effect for each demographic group. Full results from these regressions are available upon request. 
Table 4 Alternative estimates of the effect of lifetime health cover

\begin{tabular}{|c|c|c|c|c|c|}
\hline \multirow[b]{2}{*}{ Pre-LHC } & \multirow[b]{2}{*}{ Post-LHC } & \multicolumn{2}{|c|}{$\begin{array}{c}\text { Simple difference } \\
(\Delta \bar{B})\end{array}$} & \multicolumn{2}{|c|}{$\begin{array}{l}\text { Difference in difference } \\
\qquad\left(\Delta \bar{B}-\Delta \bar{B}^{*}\right)\end{array}$} \\
\hline & & Change (\$) & As $\%$ of base year & Change (\$) & As $\%$ of base year \\
\hline 1997 & 2001 & -61.93 & 9.5 & -81.80 & 12.6 \\
\hline 1997 & 2005 & -18.59 & 2.9 & -59.01 & 9.1 \\
\hline 1998 & 2001 & -70.80 & 10.5 & -85.66 & 12.8 \\
\hline 1998 & 2005 & -27.58 & 4.1 & -62.69 & 10.3 \\
\hline 1999 & 2001 & -64.33 & 10.4 & -74.39 & 13.2 \\
\hline 1999 & 2005 & -22.17 & 3.6 & -52.08 & 9.3 \\
\hline
\end{tabular}

Notes: See eqs. (5) and (6) for the decomposition formulae.

In the second 5-year period, changes in demographics and group-specific average benefits both contributed to rising spending. The decomposition results show that, ceteris paribus, the ageing of the risk pool caused benefits to increase by $\$ 43$. The counterfactual results indicate that about half of this change can be explained by the ageing of the population. Most of the increase in average benefits between 2001 and 2005, however, can be explained by rising hospital utilization - as newly insured individuals completed their probationary periods - and an increase in the mean cost per hospital episode.

The ageing of the risk pool from 2001 onward reduced, but did not eliminate, the savings that can be attributed to LHC. The decomposition results for the full period show that despite this ageing, average benefits were roughly 3 per cent lower in 2005 than they would have been had the composition of the risk pool remained constant at its 1997 level $(-\$ 18.59 / 650.12=-0.029)$. If we assume that in absence of the policy change the risk pool would have aged at the same rate as the general population, then we should subtract from this estimate $\$ 40.41$, which yields an estimated policy effect of $-\$ 59$, or roughly 9 per cent of $\bar{B}_{1997}$. Again, this is a conservative estimate since prior to the introduction of LHC the risk pool was ageing more quickly than the population.

It is clear from Table 3 that estimates of the effect of LHC are somewhat sensitive to the years chosen to calculate changes. Table 4 provides a fuller sense of this sensitivity by displaying several alternative estimates that use different years to define the pre-and post-LHC periods. The first panel repeats the results from Table 4, using 1997 as the pre-period and calculating changes to 2001 and 2005. The next two panels take 1998 and 1999 as the base year. For all years, the longer time period produces a smaller estimate because of the way that the risk pool aged after 2001. In percentage terms relative to the baseline year, the difference-indifferences estimates using 2001 as the end point range from -12 to -13 per cent. When 2005 is used as the endpoint, the differences are slightly smaller, ranging from -9 to -10 per cent. 


\section{Discussion}

Between 1984, when universal public insurance was established, and the late 1990s, the percentage of Australians with private health insurance declined steadily and the risk pool aged relative to the population. This combination is consistent with an adverse selection spiral, albeit a gradual one. The coincidence of these two trends, however, tell us little about the magnitude of adverse selection in Australia's private health insurance market in terms of its effect on critical market outcomes, such as insurance premiums or coverage rates. The analysis presented in this paper suggests that the impact of the deterioration of the risk pool on average premiums was small. I estimate that in 1997-1999 private health insurance premiums in Australia were 10 per cent higher than they would have been if the privately insured risk pool were representative of the entire population.

One goal of this analysis was to better understand the effects of the community rating rules that apply to private health insurance in Australia and elsewhere. This result suggests that community rating was not a major cause of the decline in insurance coverage. At its lowest point, the percentage of Australians with private health insurance coverage had fallen by nearly 40 per cent relative to the percentage in 1984 . Applying plausible estimates of the take-up elasticity for private health insurance, the 10 per cent increase in average premiums attributed to adverse selection can only explain a coverage decline of between 1 and 5 per cent. Moreover, there is good reason to believe that this estimate overstates the amount of adverse selection directly caused by community rating. Even if premiums were fully risk-rated, there are a number of reasons why the demand for health insurance coverage would likely increase with age. For example, the demand for insurance may increase with age because the variance in health expenditures increases with age or because older consumers have a stronger preference for health care or are more risk averse than younger ones. Indeed, in the U.S., where premiums tend to be risk-rated, private insurance coverage rates increase with age. In the specific case of Australia, older consumers may have a stronger demand for private insurance because of their experiences prior to the establishment of universal public insurance. That is, younger adults who have always known the Medicare programme may see less need to go outside the public system.

Given how much community rating raises premiums for younger consumers relative to what they would pay in a risk-rated system, it may be surprising that the effect of the policy is so small. One explanation is that the analysis presented here, like most studies of adverse selection in health insurance, focuses on the extent of adverse selection against the market (i.e. on the extensive margin) that occurs when younger consumers respond to those higher prices by dropping out of the market entirely. It is not possible with available data to analyse selection within the market (the intensive margin). As noted, Australian regulations allow insurers considerable flexibility in designing products to appeal to different risk groups. Gale ${ }^{36}$ documents a high degree of product differentiation in the market and presents data suggesting that the variation in premiums across different products reflects differences in the risk characteristics

\footnotetext{
${ }^{36}$ Gale (2005).
} 
of individuals choosing them. Similarly, Vaithianathan ${ }^{37}$ shows that in spite of community rating, younger individuals with private health insurance pay considerably less for that coverage than older persons. These patterns along with my results are consistent with results of U.S. studies that find that the imposition of community rating rules by states had no effect on the number of people with health insurance, but did affect sorting among different types of insurance plans. ${ }^{38}$

Such sorting is consistent with the type of "separating equilibrium" predicted by Rothschild and Stiglitz's ${ }^{39}$ classic model of asymmetric information in insurance markets. In the context of a regulated market like Australia's a key implication is that even if explicit risk rating is prohibited, to the extent that high- and low-risk consumers sort into different plans, risk rating will occur implicitly. The welfare implications of this sorting are not straightforward. A basic result of the Rothschild and Stiglitz model is that the inability of insurers to distinguish between high- and low-risk consumers makes low risks worse off because they purchase less insurance than they would prefer at actuarially fair rates. In the Australian context, however, it is likely that the separating equilibrium involves younger consumers foregoing benefits that they place little value on, such as coverage for cardiac care or hip replacements. More research on the welfare implications of this sorting would be valuable.

The different policies enacted in Australia in the late 1990s were designed to reverse the decline in private insurance coverage. The policy of LHC was also intended to alter the demographics of the risk pool by creating stronger incentives for younger consumers to take up and keep coverage. It is clear from the raw enrolment data that the policies had a strong effect on the level of coverage. The evidence presented here indicates that the second objective was achieved as well. Holding constant other factors, the introduction of LHC reduced average premiums by between 9 and 13 per cent - that is, enough to eliminate or nearly eliminate the effect of prior adverse selection. Five years after the policy change average benefits were less than 2 per cent higher than they would have been if the risk pool were representative of the general population in terms of age and sex. And this small difference was almost entirely offset by premium surcharge payments from subscribers who took up private coverage after the $\mathrm{LHC}$ rules were in effect.

The success of the LHC policy suggests that it represents an important model for policy makers outside Australia. As noted, a similar age-rating scheme has been proposed in Ireland and is a feature of the new Medicare prescription drug benefit. Future research on these other systems will provide additional evidence on the effect of entry-age premiums on insurance coverage and risk selection.

\section{References}

Australian Bureau of Statistics (1995) Demographic estimates and projections: Concepts, sources and methods, 1995, Information Paper 3228.0, Canberra, Australia.

Australian Industry Commission (1997) Private Health Insurance in Australia, Canberra, Australia.

\footnotetext{
37 Vaithianathan (2004).

${ }^{38}$ Buchmueller and Dinardo (2002); Buchmueller and Liu (2005/2006).

${ }^{39}$ Rothschild and Stiglitz (1976).
} 
Australian Institute of Health and Welfare (2006) Australian hospital statistics, 2004-05, Health Services Series No. 26, Canberra: Australian Institute of Health and Welfare, pp. 1-371.

Barrett, G. and Conlon, R. (2003) 'Adverse selection and the decline of health insurance coverage in Australia: 1989 to 1995', The Economic Record 79(246): 279-296.

Blumberg, L., Nichols, L. and Banthin, J. (2001) 'Worker decisions to purchase health insurance', International Journal of Health Care Finance and Economics 1: 305-325.

Brown, H.S. and Connelly, L.B. (2005) 'Lifetime cover in private insurance markets', International Journal of Health Care Finance and Economics 5: 75-88.

Brown, H.S. and Connelly, L.B. (2006) 'Lifetime subsidies in Australian private health insurance markets with community rating', The Geneva Papers on Risk and Insurance - Issues and Practice 31: 705-719.

Buchmueller, T.C., Couffinhal, A., Grignon, M. and Perronnin, M. (2004) 'Access to physician services: Does supplemental insurance matter? Evidence from France', Health Economics 13: 669-687.

Buchmueller, T.C. and Dinardo, J. (2002) 'Did community rating induce an adverse selection death spiral? Evidence from New York, Pennsylvania and Connecticut', American Economic Review 92: 280-294.

Buchmueller, T.C. and Jensen, G.A. (1997) 'Small group reform in a competitive managed care market: The case of California, 1993-1995', Inquiry 34: 249-263.

Buchmueller, T.C. and Liu, S. (2005/2006) Health insurance reform and HMO penetration in the small group market, NBER Working Paper No. W11446, Washington, DC.

Buchmueller, T.C. and Ohri, S. (2006) 'Health insurance take-up by the near-elderly', Health Services Research 41: 2054-2073.

Butler, J.R. (1999) Estimating elasticities of demand for private health insurance in Australia, National Centre for Epidemiology and Population Health Working Paper no. 43, The Australian National University, Canberra.

Butler, J.R. (2002) 'Policy change and private health insurance: Did the cheapest policy do the trick?', Australian Health Review 25: 33-41.

Chernew, M., Frick, K. and McLaughlin, C. (1997) 'The demand for health insurance coverage by low-income workers: Can reduced premiums achieve full coverage?', Health Services Research 32: 453-470.

Colombo, F. and Tapay, N. (2003) Private health insurance in Australia: A case study, OECD Health Working Paper no. 8, Paris: OECD.

Doiron, D., Jones, G. and Savage, E. (2008) 'Healthy, wealthy and insured? The role of self-assessed health in the demand for private health insurance', Health Economics 17: 317-334.

Ellis, R.P. and Savage, E. (2005) Where do you run after you run for cover? The impact of premium changes on the characteristics of the privately insured in Australia, Unpublished manuscript, Centre for Health Economics Research and Evaluation, University of Technology, Sydney.

Ettner, S. (1997) 'Adverse selection and the purchase of medigap insurance by the elderly', The Journal of Health Economics 16: 543-562.

Fang, H., Keane, M. and Silverman, D. (2006) Sources of advantageous selection: Evidence from the medigap insurance market, NBER Working Paper No. 12289, Washington, DC.

Frech, H., Hopkins, S. and McDonald, G. (2003) 'The Australian private health insurance boom: Was it subsidies or liberalized regulation?', Economic Papers 22: 58-64.

Gale, A. (2005) What price health? Private health insurance cost pressures and product pricing, Unpublished manuscript, Institute of Actuaries of Australia.

Gale, A. and Brown, A. (2003) Health after lifetime cover: Recent health insurance experience, Unpublished manuscript, Institute of Actuaries of Australia, Sydney.

Gans, J.A. and King, S.P. (2003) 'Anti-insurance: Analysing the health insurance system in Australia', The Economic Record 79(247): 473-486.

Hall, J., De Abreau Lourenco, R. and Viney, R. (1999) 'Carrots and sticks-the fall and fall of private health insurance in Australia', Health Economics 8: 653-660.

Hall, J. and Savage, E. (2005) 'An unhealthy conflict: Private interests and the public purse', in A. Maynard (ed) The Public-Private Mix for Health, Abingdon, UK: Radcliffe Publishing.

Harper, I.R. (2003) 'Health sense: When spending money saves money', Policy 19: 19-24. 
Herring, B. and Pauly, M.V. (2001) 'Premium variation in the individual health insurance market', International Journal of Health Care Finance and Economics 1: 43-58.

Hindle, D. and McAuley, I. (2004) 'The effects of private health insurance: A review of the evidence', Australian Health Review 28: 119-138.

Hurd, M.D. and McGarry, K. (1997) 'Medical insurance and the use of health care services by the elderly', The Journal of Health Economics 16: 129-154.

Marquis, M.S. and Long, S.H. (2001) 'Effects of 'second generation' small group health insurance market reforms, 1993 to 1997', Inquiry 38: 365-380.

Monheit, A. and Schone, B. (2004) 'How has small group market reform affected employee health insurance coverage', Journal of Public Economics 88: 237-254.

Palangkaraya, A. and Yong, J. (2005) 'Effects of recent carrot-and-sticks policy initiatives on private health insurance coverage in Australia', The Economic Record 81: 262-272.

Palangkaraya, A. and Yong, J. (2007) 'How effective is 'lifetime health cover' in raising private health insurance coverage in Australia? An assessment using regression discontinuity', Applied Economics 39: 1361-1374.

Pauly, M.V. and Herring, B. (1999) Pooling Health Insurance Risks, Washington, DC: AEI Press.

Private Health Insurance Administration Council (PHIAC) (2006) Operations of the Registered Health Benefits Organizations Annual Report, 2005-06, PHIAC, Kingston, Australia.

Rothschild, M. and Stiglitz, J. (1976) 'Equilibrium in competitive insurance markets: An essay on the economics of imperfect information', Quarterly Journal of Economics 90: 630-649.

Shmueli, A. (2001) 'The effect of health on acute care supplemental insurance ownership: An empirical analysis', Health Economics 10: 341-350.

Simon, K. (2004) 'Adverse selection in health insurance markets? Evidence from state small-group health insurance reforms', Journal of Public Economics 89: 1865-1877.

Vaithianathan, R. (2004) 'A critique of the private health insurance regulations', The Australian Economic Review 37: 257-270.

Zuckerman, S. and Rajan, S. (1999) 'An alternative approach to measuring the effects of insurance market reforms', Inquiry 36: 44-56.

\section{About the Author}

Thomas Buchmueller is an economist whose research focuses mainly on the economics of health insurance and related public policy issues. He is the Waldo O. Hildebrand Professor of Risk Management and Insurance at the University of Michigan's Ross School of Business and a Research Associate of the National Bureau of Economic Research. 